\title{
Primary pulmonary synovial sarcoma requiring differentiation from pulmonary metastasis of tibial adamantinoma: a case report
}

\author{
Toshiharu Shirai ${ }^{1,2^{*}}$, Shinji Tsuchida ${ }^{1}$, Ryu Terauchi ${ }^{1}$, Naoki Mizoshiri ${ }^{1}$, Eiichi Konishi ${ }^{3}$, Yasuhiko Tomita ${ }^{4}$,
} Junichi Shimada ${ }^{5}$, Hiroyoshi Fujiwara ${ }^{1}$ and Toshikazu Kubo ${ }^{1}$

\begin{abstract}
Background: Primary pulmonary synovial sarcoma (PPSS) is rare. We describe a case of PPSS complicated by tibial adamantinoma that required differentiation from lung metastasis.

Case presentation: A 39-year-old Japanese woman presented with hemoptysis, dyspnea, and a well-defined tumor measuring $3.0 \mathrm{~cm}$ in greatest diameter in the right lower lobe on chest computed tomography (CT). Positron emission tomography/CT with fluorodeoxyglucose (FDG-PET/CT) showed mild uptake of FDG (maximum standardized uptake value of 2.0). Her past history included surgery for adamantinoma of the right tibia at age 25 years. We considered the possibility of pulmonary metastasis from the adamantinoma and performed fluoroscopy-assisted thoracoscopic resection of the tumor after CT-guided Lipiodol marking. Histologically, the tumor was composed mainly of a dense proliferation of spindle cells. Immunohistochemical studies were positive for epithelial membrane antigen, B cell lymphoma 2, and transducing-like enhancer of split 1. They were negative for CD34. The synovial sarcoma, $x$ breakpoint 1 gene-fusion transcript was detected by reverse transcription-polymerase chain reaction. It is diagnostic of PPSS. Resection margins were negative. The patient was well without evidence of recurrence or metastasis of the PPSS or adamantinoma at the 30-month and 15-year follow-ups.

Conclusion: Clinical and radiological manifestations of PPSS overlap with those of other lung tumors. The solitary pulmonary nodule in this case was indistinguishable from pulmonary metastases of the adamantinoma based on clinical symptoms, epidemiology, chest radiography, CT, and FDG-PET/CT. PPSS was diagnosed only after evaluating gross pathology, histology, immunohistochemistry, and cytogenetics. PPSS should be included in the differential diagnosis of a well-defined homogeneous round or oval lung mass. To our knowledge, this is the first report of PPSS complicated by adamantinoma.
\end{abstract}

Keywords: Primary pulmonary synovial sarcoma, Adamantinoma, Pulmonary bone tumor metastasis

\section{Background}

Most lung tumors are malignant, carcinomatous metastases from other tissue cancers, such as bone tumors. Primary lung sarcoma is rare, accounting for less than $0.5 \%$ of all lung tumors $[1,2]$. The variety of soft tissue sarcomas reflects the range of mesenchymal tissues present in the lung.

\footnotetext{
* Correspondence: shi-ra-e@koto.kpu-m.ac.jp

'Department of Orthopaedics, Graduate School of Medical Science, Kyoto Prefectural University of Medicine, Kawaramachi-Hirokoji, Kamigyo-ku, Kyoto 602-8566, Japan

2Department of Orthopaedic Surgery, Graduate School of Medical Science, Kanazawa University, 13-1 Takara-machi, Kanazawa, 920-8641, Japan Full list of author information is available at the end of the article
}

These sarcomas include extraskeletal Ewing's sarcoma, malignant fibrous histiocytoma, and synovial sarcoma. The latter is a rare sarcoma accounting for approximately $8 \%$ of soft tissue sarcomas. Although synovial sarcoma predominantly affects the extremities of young adults, primary lesions have also been identified in the head and neck, abdominal wall, and thorax (including the mediastinum, pericardium, pleura, and lung) [3-5]. A recent MEDLINE search revealed approximately 92 cases of primary pulmonary synovial sarcoma (PPSS) reported worldwide during the last three and a half decades. There were no reports, however, of PPSS complicated by a primary bone 
tumor. Here we report a woman with PPSS that required differentiation from tibial adamantinoma metastasis.

\section{Case presentation}

\section{Initial presentation and diagnostics}

A 39-year-old Japanese woman, who was a household helper, presented to a community hospital with hemoptysis and dyspnea. Other symptoms, such as cough and chest pain, were not presented. She reported a family history of stomach cancer (her father). She had smoked one or two cigarettes daily for the last 19 years. There was no history of asbestos exposure or tuberculosis. She had undergone wide resection of an adamantinoma of the right tibia and limb salvage with an uncemented megaprosthesis (Howmedica Modular Replacement System; Howmedica International, Limerick, Ireland) 15 years previously (Figure 1). Her vital signs and clinical examination results were unremarkable. A general survey revealed no clubbing and no palpable cervical or axillary lymph nodes. Sputum was negative for acid-fast bacilli. The serum tumor marker levels were within their respective normal ranges.

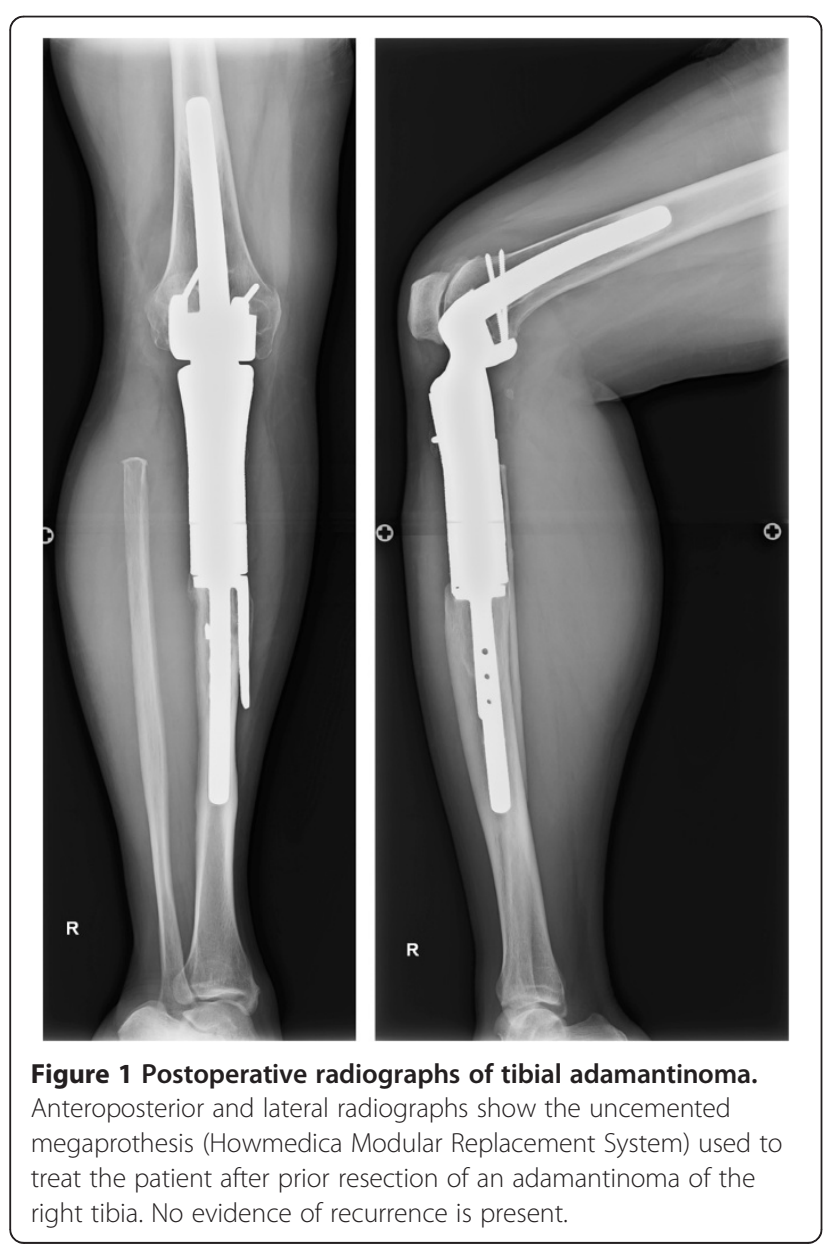

Chest radiography demonstrated a mass in the right lower field without pleural effusion. Computed tomography $(\mathrm{CT})$ of the lung revealed a mass measuring $2.5 \times$ $3.0 \mathrm{~cm}$ that had no contact with the pleura, main bronchus, inferior pulmonary vein, or right atrium (Figure 2a). Bronchoscopy did not reveal any abnormalities. Positron emission tomography (PET)/CT with fluorodeoxyglucose (FDG) showed mild FDG uptake, with a maximum standardized uptake value (SUVmax) of 2.0 (Figure 2b).

\section{Treatment}

Because the tumor was suspected to be a pulmonary metastasis from the earlier adamantinoma, we surgically resected it without prior biopsy. The procedure was as follows. The pulmonary nodule was marked with $0.4 \mathrm{~mL}$ of Lipiodol $^{\odot}$ (Laboratoire Guerbet, Roissy, France) under CT guidance. The visceral pleura near the nodule was marked with $1 \mathrm{~mL}$ of a mixture of atelocollagen and methylene blue. During the thoracoscopic surgery performed 1 day later, the marked nodule was grasped with ring-shaped forceps under $\mathrm{C}$-arm fluoroscopic guidance and resected $[6,7]$.

\section{Histology}

Histopathologically, the tumor showed densely proliferated spindle cells with a high mitosis rate (Figure 3a). The immunohistochemical workup revealed that the spindle cell component was positive for B cell lymphoma 2 (BCL-2), pancytokeratin (MNF116) directed to cytokeratins $5,6,8,17$, and 19, transducin-like enhancer of split 1 (TLE-1), and epithelial membrane antigen (EMA). It was negative for CD34 (Figure 3b-d). The synovial sarcoma, $X$ breakpoint 1 (SYT-SSX1) fusion gene was detected by reverse transcription-polymerase chain reaction using ribonucleic acid samples from the tumor tissue. Hence, the final diagnosis was PPSS. Resection margins were negative.

\section{Follow-up}

The patient's hemoptysis and dyspnea resolved after the surgical procedure. Because the patient had factors indicating a poor PPSS prognosis, including her age ( $>20$ years), sex, and the presence of the SYT-SSX1 variant gene, we recommended chemotherapy with a combination of ifosfamide and doxorubicin. She refused further treatment, however. Follow-up visits were undertaken every 3 months after the surgery. She has remained well without evidence of recurrence or metastasis of the PPSS or the adamantinoma at the 30-month follow-up.

\section{Discussion}

Soft tissue synovial sarcoma is a clinicopathologically and cytogenetically distinctive neoplasm that mainly affects deep soft tissues of the extremities in adolescents and young adults. Synovial sarcoma is also recognized as 

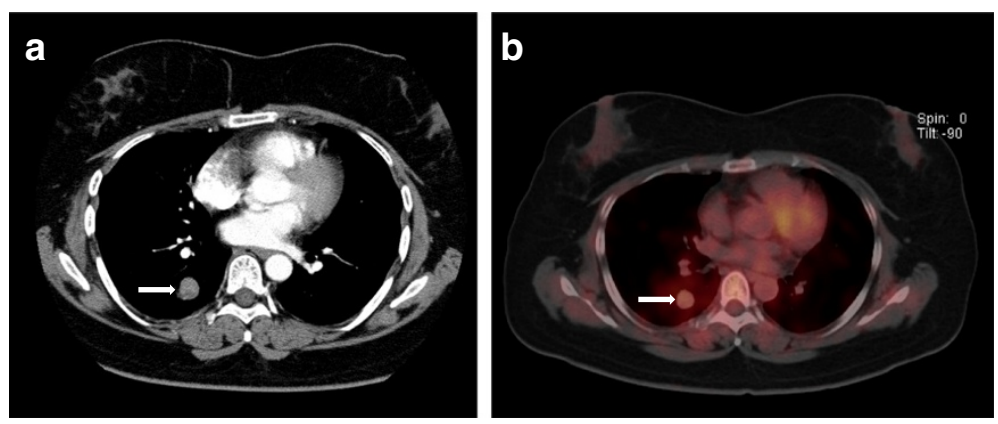

Figure 2 Preoperative computed tomography and positron emission tomography with fluorodeoxyglucose. Axial section of computed tomography (a) and positron emission tomography/computed tomography with fluorodeoxyglucose (b) show slightly high uptake by the right lung mass (arrow).

a primary pulmonary neoplasm [8]. PPSS is an aggressive tumor whose histological features are also seen in soft tissue synovial sarcoma [9]. PPSS occurs in older patients as well, however, in contrast to other soft tissue synovial sarcomas, with patients' ages ranging from 9 to 84 years (mean 43 years) without sex bias [3-5]. Hartel et al. [10] reported that clinical symptoms are dyspnea $(42 \%)$, chest pain (39\%), cough (32\%), and hemoptysis (22\%). There are few asymptomatic cases. Most PPSSs are located in the lung parenchyma (58\%), pleura (33\%), and mediastinum (9\%). Rarely, they extend into the bronchial tree or occur in the heart or pericardium $[3,4,8,11]$. PPSS lesions range in size from 0.6 to $27.0 \mathrm{~cm}$ (mean $6.8 \mathrm{~cm})[4,10]$. Radiologically, in contrast to soft tissue synovial sarcoma, PPSS is typically uniform with wellcircumscribed rounded or lobulated borders [12,13]. The contralateral lung usually appears normal, although mediastinal shift may occur in the presence of an extremely large mass [11]. CT demonstrates a well-defined homogeneous or heterogeneously enhancing mass containing necrotic areas and soft tissue components with common ipsilateral pleural effusion [11,12]. Similar to all sarcomas, metastasis occurs via the blood, and adenopathy is uncommon. Endobronchial invasion is also not common, unlike lung carcinoma $[11,14]$. Because of their high metabolic activity, these lesions show increased FDG uptake (SUVmax of > 2.5) on PET/CT [15].

Adamantinoma, in contrast, is a low-grade neoplasm that affects long bones and accounts for less than $1 \%$ of all primary bone tumors. These lesions occur most commonly in patients $10-50$ years of age with slight male preponderance $[16,17]$. They are locally aggressive. The

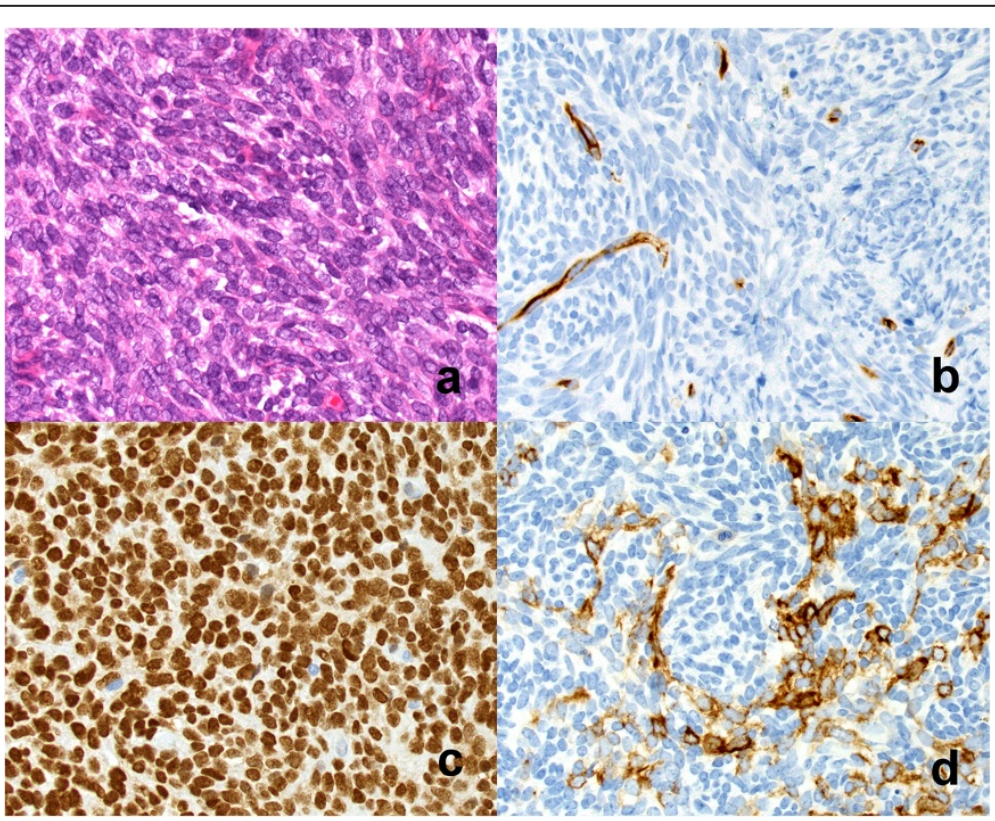

Figure 3 Histology. (a) Photomicrograph shows histopathological features of spindle cell sarcoma (H\&E, $\times 20)$. (b-d) Photomicrograph shows spindle cells positive for the presence of CD34, transducin-like enhancer of split 1, and pancytokeratin. 
incidence of recurrence is approximately $30 \%$, and that of metastases ranges between $10 \%$ and $20 \%[16,17]$. They are capable of sending off distant metastases, especially to the lung [18]. It is not uncommon to develop pulmonary metastases even up to 10 years after detection of the primary lesion [19]. Radiologically, the tumor is typically uniform, well circumscribed, and similar to other pulmonary metastases of bone tumors. Pulmonary metastases of adamantinomas range in size from 0.4 to $10.0 \mathrm{~cm}$ (mean $4.7 \mathrm{~cm})$ [16-19].

We considered pulmonary metastasis of adamantinoma in the differential diagnosis of our case because of the CT and FDG-PET/CT findings, the past history of adamantinoma, and the lack of reports of PPSS in conjunction with another tumor in the literature. Metastatectomy to remove pulmonary adamantinoma lesions with good results has been reported [19]. There appears to be no definitive role for radiotherapy or chemotherapy [20]. We therefore performed fluoroscopy-assisted thoracoscopic resection of the small pulmonary tumor in our patient. Unexpectedly, the final diagnosis based on histological findings and cytogenetic analysis was PPSS. Matsuo et al. [21] concluded that, although rare, PPSS should be included in the differential diagnosis of a well-defined homogeneous, round lung mass on CT images. However, the clinical and radiological manifestations of PPSS overlap with those of other lung lesions, including malignant melanoma, epithelioid schwannoma, malignant fibrous histiocytoma, malignant mesothelioma, adenocarcinoma, carcinosarcoma, lung hydatid disease, metastatic carcinoma, bronchogenic carcinoma, mesothelioma, lymphoma, Wegener's granulomatosis, pyogenic abscess, intrapulmonary hematoma, rheumatoid nodules, histoplasmosis, coccidioidomycosis, and bone tumor metastasis $[15,22]$. These primary lung lesions are typically indistinguishable from PPSS based on clinical symptoms, epidemiology, chest radiography, CT, and FDG-PET/CT [12,23]. To reach a correct diagnosis, the $\mathrm{t}(\mathrm{X} ; 18)(\mathrm{p} 11.2 ; \mathrm{q} 11.2)$ chromosomal translocation should be demonstrated by cytogenetic testing. This analysis is the only primary test for diagnosing synovial sarcoma $[9,15]$. According to Akerman et al. [24], the diagnosis of synovial sarcoma in large lesions $(>3 \mathrm{~cm})$ may be suggested in fine-needle aspiration biopsy specimens, but adjunctive methods are necessary for a definitive diagnosis. As a result, it may be that only after surgery is it possible to diagnose a small PPSS that has no contact with other internal organs, as in our case.

Because of its rarity and the paucity of data regarding its natural history, there are no guidelines regarding the optimal treatment for PPSS. Current treatment thus includes surgical resection (lobectomy or pneumonectomy) [25]. In our case, complete surgical excision of PPSS was performed by fluoroscopy-assisted thoracoscopic resection.
Patient age, a positive surgical margin, and tumor size help guide the decision about whether additional adjuvant chemotherapy and/or radiation therapy is needed [25]. The overall 5-year survival rate for those with PPSS is $50 \%$. Factors that indicate a poor prognosis include age $>20$ years, female sex, tumor size $>5 \mathrm{~cm}$, positive resection margin, extensive tumor necrosis, high number of mitoses ( $>10$ per 10 high-power fields), neurovascular invasion, and the presence of the SYT-SSX1 variant gene [25]. Although our patient had several factors that put her at risk of a poor prognosis, she experienced no recurrence during 30 months of postoperative follow-up.

We had recommended that our patient undergo chemotherapy with ifosfamide and doxorubicin, but she refused further treatment. We also suggested pazopanib, which interferes with vascular endothelial growth factor and platelet-derived growth factor pathways. Pazopanib is the first nonchemotherapeutic anticancer agent approved by regulatory authorities for soft tissue sarcoma and to which pulmonary adamantinoma metastasis responds [26,27]. Long-term follow-up is necessary for patients with a soft tissue sarcoma.

\section{Conclusions}

This is the first report of PPSS complicated by tibial adamantinoma, which is a low-grade malignant primary bone tumor. PPSS is a rare tumor without specific symptoms, signs, or radiological features. The role of functional imaging has not yet been evaluated, and the diagnosis is usually based on histopathological examination or cytogenetic testing of the resected tumor. The diagnosis of PPSS before surgery also may not be possible, as in our patient. Along with pulmonary metastasis from a bone tumor, PPSS should be included in the differential diagnosis of a well-defined homogeneous round or oval lung mass.

\section{Consent}

Written informed consent was obtained from the patient for publication of this Case Report and any accompanying images. A copy of the written consent form from our university hospital is available for review by the Editorin-Chief of this journal.

\section{Abbreviations \\ PPSS: Primary pulmonary synovial sarcoma; CT: Computed tomography; PET: Positron emission tomography; FDG: Fluorodeoxyglucose; SUVmax: Maximum standardized uptake value; BCL-2: B cell lymphoma 2; MNF116: Pancytokeratin; TLE-1: Transducin-like enhancer of split 1; EMA: Epithelial membrane antigen; SYT-SSX1: Synovial sarcoma, X breakpoint 1.}

\section{Competing interests}

The authors declare that they have no competing interests.

\section{Authors' contributions}

TS drafted and wrote the manuscript, did the literature research, and conducted all follow-up examinations of the patient and documented the 
data. ST assisted drafting and writing the manuscript. RT substantially contributed to the structure of the manuscript. NM prepared the medical imaging section including radiological images. EK produced the histopathological diagnosis and images. YT performed the cytogenetic analysis to determine the final diagnosis. JS was responsible for informed consent of the patient and treated the patient. HF was responsible for reviewing the manuscript. TK leads the oncologic orthopedic section of our institution. All authors read and approved the final manuscript.

\section{Acknowledgments}

This research received no specific grant from any funding agency in the public, commercial, or not-for-profit sectors.

\section{Author details}

${ }^{1}$ Department of Orthopaedics, Graduate School of Medical Science, Kyoto Prefectural University of Medicine, Kawaramachi-Hirokoji, Kamigyo-ku, Kyoto 602-8566, Japan. ²Department of Orthopaedic Surgery, Graduate School of Medical Science, Kanazawa University, 13-1 Takara-machi, Kanazawa, 9208641, Japan. ${ }^{3}$ Department of Surgical Pathology, Graduate School of Medical Science, Kyoto Prefectural University of Medicine, Kawaramachi-Hirokoji, Kamigyo-ku, Kyoto 602-8566, Japan. ${ }^{4}$ Department of Pathology, Osaka Medical Center for Cancer and Cardiovascular Diseases, 1-3-3 Nakamichi, Higashinari-ku, Osaka 537-8511, Japan. ${ }^{5}$ Department of General Thoracic Surgery, Graduate School of Medical Science, Kyoto Prefectural University of Medicine, Kawaramachi-Hirokoji, Kamigyo-ku, Kyoto 602-8566, Japan.

Received: 30 July 2014 Accepted: 2 October 2014

Published: 18 October 2014

\section{References}

1. Etienne-Mastroianni B, Falchero L, Chalabreysse L, Loire R, Ranchere D, Souquet PJ, Cordier JF: Primary sarcomas of the lung: a clinicopathologic study of 12 cases. Lung Cancer 2002, 38:283-289.

2. Mankin HJ, Hornicek FJ: Diagnosis, classification, and management of soft tissue sarcomas. Cancer Control 2005, 12:5-21.

3. Barosa J, Ribeiro J, Afonso L, Fernandes J, Monteiro E: Head and neck sarcoma: analysis of 29 cases. Eur Ann Otorhinolaryngol Head Neck Dis 2014, 131:83-86.

4. Begueret $\mathrm{H}$, Galateau-Salle F, Guillou L, Chetaille B, Brambilla E, Vignaud JM, Terrier P, Groussard O, Coindre JM: Primary intrathoracic synovial sarcoma: a clinicopathologic study of $40 \mathrm{t}(\mathrm{X} ; 18)$-positive cases from the French Sarcoma Group and the Mesopath Group. Am J Surg Pathol 2005, 29:339-346

5. Fetsch JF, Meis JM: Synovial sarcoma of the abdominal wall. Cancer 1993, 72:469-477.

6. Watanabe K, Nomori H, Ohtsuka T, Kaji M, Naruke T, Suemasu K: Usefulness and complications of computed tomography-guided lipiodol marking for fluoroscopy-assisted thoracoscopic resection of small pulmonary nodules: experience with 174 nodules. J Thorac Cardiovasc Surg 2006, 132:320-324.

7. Yamagami T, Yoshimatsu R, Miura H, Tanaka O, Shimada J, Kato D, Nakamura T, Yamada K, Awai K: Pneumonia occurring after injection of Lipiodol to localize pulmonary nodules before fluoroscopy-aided thoracoscopic resection. Acta Radio/ Short Rep 2014, 3:2047981613499754

8. Travis WD BE, Muller-Hermelink HK, Harris CC: World Health Organization Classification of Tumors. Pathology and Genetics of Tumors of the Lung, Pleura, Thymus, and Heart. Lyon France: IARG press; 2004:344.

9. Okamoto S, Hisaoka M, Daa T, Hatakeyama K, Iwamasa T, Hashimoto H: Primary pulmonary synovial sarcoma: a clinicopathologic, immunohistochemical, and molecular study of 11 cases. Hum Pathol 2004, 35:850-856.

10. Hartel PH, Fanburg-Smith JC, Frazier AA, Galvin JR, Lichy JH, Shilo K, Franks TJ: Primary pulmonary and mediastinal synovial sarcoma: a clinicopathologic study of 60 cases and comparison with five prior series. Mod Pathol 2007, 20:760-769.

11. Essary LR, Vargas SO, Fletcher CD: Primary pleuropulmonary synovial sarcoma: reappraisal of a recently described anatomic subset. Cancer 2002, 94:459-469.

12. Duran-Mendicuti A, Costello P, Vargas SO: Primary synovial sarcoma of the chest: radiographic and clinicopathologic correlation. J Thorac Imaging 2003, 18:87-93.
13. Nicholson AG, Goldstraw P, Fisher C: Synovial sarcoma of the pleura and its differentiation from other primary pleural tumours: a clinicopathological and immunohistochemical review of three cases. Histopathology 1998, 33:508-513.

14. Régnard JF, Icard P, Guibert $L$, de Montpreville VT, Magdeleinat $P$, Levasseur P: Prognostic factors and results after surgical treatment of primary sarcomas of the lung. Ann Thorac Surg 1999, 68:227-231.

15. Frazier AA, Franks TJ, Pugatch RD, Galvin JR: From the archives of the AFIP: Pleuropulmonary synovial sarcoma. Radiographics 2006, 26:923-940.

16. Kanakaraddi SV, Nagaraj G, Ravinath TM: Adamantinoma of the tibia with late skeletal metastasis: an unusual presentation. J Bone Joint Surg Br 2007, 89:388-389.

17. Filippou DK, Papadopoulos V, Kiparidou E, Demertzis NT: Adamantinoma of tibia: a case of late local recurrence along with lung metastases. J Postgrad Med 2003, 49:75-77.

18. Ramesh R, Burrah R, Thambuchetty N, Shivakumar K, Ananthamurthy A, Manjunath S: Adamantinoma of the tibia: a case report. Indian J Surg Oncol 2012, 3:239-241.

19. Van Schoor JX, Vallaeys JH, Joos GF, Roels HJ, Pauwels RA, Van Der Straeten ME: Adamantinoma of the tibia with pulmonary metastases and hypercalcemia. Chest 1991, 100:279-281.

20. Jain D, Jain VK, Vasishta RK, Ranjan P, Kumar Y: Adamantinoma: a clinicopathological review and update. Diagn Pathol 2008, 3:8.

21. Matsuo Y, Sakai S, Yabuuchi H, Soeda H, Takahashi N, Okafuji T, Yoshimitsu K, Koga H, Yoshino I, Oda Y, Nakamura Y, Honda H: A case of pulmonary synovial sarcoma diagnosed with detection of chimera gene: imaging findings. Clin Imaging 2006, 30:60-62.

22. Mirzoyan M, Muslimani A, Setrakian S, Swedeh M, Daw HA: Primary pleuropulmonary synovial sarcoma. Clin Lung Cancer 2008, 9:257-261.

23. Gimenez A, Franquet T, Prats R, Estrada P, Villalba J, Bague S: Unusual primary lung tumors: a radiologic-pathologic overview. Radiographics 2002, 22:601-619.

24. Akerman M, Willen $\mathrm{H}$, Carlen B, Mandahl N, Mertens F: Fine needle aspiration (FNA) of synovial sarcoma-a comparative histologicalcytological study of 15 cases, including immunohistochemical, electron microscopic and cytogenetic examination and DNA-ploidy analysis. Cytopathology 1996, 7:187-200.

25. Giaj Levra M, Novello S, Scagliotti GV, Papotti M, Le Cesne A: Primary pleuropulmonary sarcoma: a rare disease entity. Clin Lung Cancer 2012, 13:399-407.

26. Schoffski P, Cornillie J, Wozniak A, Li H, Hompes D: Soft tissue sarcoma: an update on systemic treatment options for patients with advanced disease. Oncol Res Treat 2014, 37:355-362.

27. Cohen Y, Cohen JE, Zick A, Orevi M, Doviner V, Rubinstein R, Goldshmidt H, Peylan-Ramu N, Katz D: A case of metastatic adamantinoma responding to treatment with pazopanib. Acta Oncol 2013, 52:1229-1230.

\section{doi:10.1186/1756-0500-7-736}

Cite this article as: Shirai et al:: Primary pulmonary synovial sarcoma requiring differentiation from pulmonary metastasis of tibial adamantinoma: a case report. BMC Research Notes 2014 7:736.

\section{Submit your next manuscript to BioMed Central and take full advantage of:}

- Convenient online submission

- Thorough peer review

- No space constraints or color figure charges

- Immediate publication on acceptance

- Inclusion in PubMed, CAS, Scopus and Google Scholar

- Research which is freely available for redistribution 